\title{
Coevolution between Human's Anticancer Activities and Functional Foods from Crop Origin Center in the World
}

\author{
Ya-Wen Zeng ${ }^{1 *}$, Juan Du ${ }^{1}$, Xiao-Ying Pu ${ }^{1}$, Jia-Zhen Yang², Tao Yang ${ }^{1}$, Shu-Ming \\ Yang $^{1}$, Xiao-Meng Yang ${ }^{1}$
}

\begin{abstract}
Cancer is the leading cause of death around the world. Anticancer activities from many functional food sources have been reported in years, but correlation between cancer prevalence and types of food with anticancer activities from crop origin center in the world as well as food source with human migration are unclear. Hunger from food shortage is the cause of early human evolution from Africa to Asia and later into Eurasia. The richest functional foods are found in crop origin centers, housing about $70 \%$ in the world populations. Crop origin centers have lower cancer incidence and mortality in the world, especially Central Asia, Middle East, Southwest China, India and Ethiopia. Asia and Africa with the richest anticancer crops is not only the most important evolution base of humans and origin center of anticancer functional crop, but also is the lowest mortality and incidence of cancers in the world. Cancer prevention of early human migrations was associated with functional foods from crop origin centers, especially Asia with four centers and one subcenter of crop origin, accounting for $58 \%$ of the world population. These results reveal that coevolution between human's anticancer activities associated with functional foods for crop origin centers, especially in Asia and Africa.
\end{abstract}

Keywords: Cancer prevention-functional foods-coevolution-crop origin-human migration-anticancer crop

Asian Pac J Cancer Prev, 16 (6), 2119-2128

\section{Introduction}

Functional foods for prevention of chronic diseases is one of this century's key global challenges, which is natural bioactive products with food value and promising therapeutic properties in cancer and so on (Ranzato et al., 2014). Cancer is not only the first leading cause of death worldwide and accounting for 8.2 million deaths in 2012, but also has diet as one of the most important modifiable risk factors (Zeng et al., 2013). About $30 \%$ of cancer deaths are due to the five leading behavioral and dietary risks, especially tobacco use, low fruit and vegetable intake. Yunnan Province is the lowest mortality of cancers (0.541\%o) in China, especially esophageal cancer, gastric cancer, liver cancer, leukemia, female breast cancer, and cervical cancer (Zhou et al., 2010); Southwest China (especially Yunnan Province) is a center of human's anticancer activities associated functional foods from crop origin center (Zeng et al., 2013).

Whether rice and barley or fruits and vegetables, bioactive phytochemicals in functional foods for cancer prevention has been notablely advanced, such as dietary anthocyanins, $\beta$-glucans, phenols and so on have potential to prevent cancers. Black rice anthocyanins possess anti-metastasis potential against human breast cancer cells (Luo et al., 2014). $\beta$-glucan from the cell walls of barley, oat, mushrooms and so on is used as the design of new therapeutic strategies against cancer (Albeituni et al., 2013). Apples with flavonoids and phenolic acids has the chemopreventive activity against carcinogenesis (Ribeiro et al., 2014). The pomegranate whole seed ethanolic extract to prevent cancer due to three bioactive compounds and the remarkable anti-proliferative activity (Lucci et al., 2015). There are the most richest in food types in Vavilov's eight crop origin centers, which has been the best survival regions of early humans migration and modern humans about $70 \%$ in the world populations, but coevolution between human's anticancer activities and functional foods from crop origin center is unclear.

\section{Human's Evolution and Crop Origin}

Hunger is the cause of migration and evolution for early humans

Dmanisi in Georgia documents that Homo outside Africa around 1800 thousand years ago (kya), with phylogeographic continuity across continents (Lordkipanidze et al., 2013). The wider diet of early humans would have provided more calories and nutrients, increasing fertility, decreasing mortality and supporting

${ }^{1}$ Biotechnology and Genetic Resources Institute, Yunnan Academy of Agricultural Sciences, ${ }^{2}$ Kuming Tiankang Science and Technology Limited Company/Agricultural Biotechnology Key Laboratory of Yunnan Province, Kunming, China *For correspondence:zengyw1967@126.com. 
large population sizes, allowing them to out-compete Neanderthals (Henry et al., 2014) and Out of Africa. The early modern human was related to the ancestors of Asians and Native Americans but had already diverged genetically from the ancestors of Europeans (Fu et al., 2013). The western Eurasian genetic signatures in modern-day Native Americans derive from post-Columbian admixture and a mixed ancestry of the First Americans (Raghavan et al., 2014). An allele frequency difference between Yoruba of Nigeria and Han Chinese is found for EDA2R and AR genes (Casto et al., 2012). Modern humans migration was the earliest coastal route from Africa into Southeast Asia by way of Indian subcontinent some 60 kya (Zhang et al., 2013). The early northward dispersal of Y-chromosome haplogroup N-M231 started from southern China about 21 kya, expanding into northern China 12-18 kya, reaching north to Siberia around 12-14 kya, westward into Central Asia and eastern/northern Europe about 8.0-10.0 kya (Shi et al., 2013). The food structure of the Neolithic may have resulted in genes associated with immunity and diet (Olalde et al., 2014). In a word, hunger for food shortage is the cause of early humans evolution, however crop origin centers with the richest in foods were the best habitable regions of human migration.

Coevolution between anticancer activities and functional foods of crop origin centers

Evolution creates bodies and forms and new abilities, love is an emotion accompanying sexuality and main physiological driving force responsible for the origin and the evolution of humanity (Burunat, 2014). Transposable elements expression and function in the central nervous system have major implications for understanding the neuroplasticity of the brain, which could have a role in shaping individual behavior and contribute to vulnerability to disease (Reilly et al., 2013). Europeans have three times more Neanderthal variants in genes involved in lipid catabolism than Asians and Africans (Khrameeva et al., 2014).

Disease prevention of early human migrations were associated with functional foods from Vavilov's eight centers of crop origin (See Figure 1). Neuropsin is a secreted-type serine protease involved in learning and

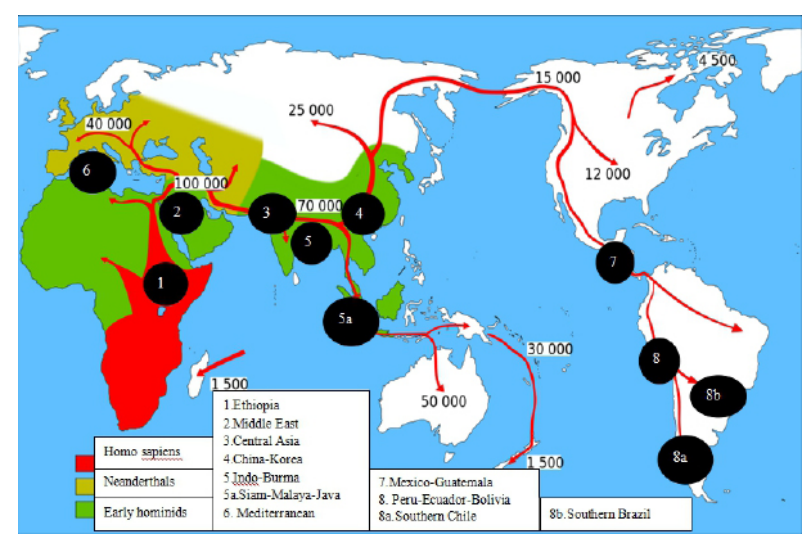

Figure 1. A map of Early Human Migrations (Burenhult, 2000) and Vavilov's Eight Centers of Crop Origin (Ladizinsky, 1998; Wikipedia, 2013) memory, which it might contribute to the progressive change of cognitive abilities during primate evolution (Li et al., 2004); The metabolite concentrations evolved rapidly over the course of human evolution in the brain and muscle (Bozek et al., 2014), however change of food structure especially brown rice to white rice and whole wheat to white flour is the cause of bursting for major chronic diseases driving force for human evolution (Zeng et al., 2011; 2012; 2013). Human's cancer activities may confer advantageous traits during early human evolution (Zhang et al., 2014).

We suggest not only that coevolution between anticancer of humans associated with major functional foods for Vavilov's eight centers of anticancer crop origin (see Figure1), but also there are lower cancer incidence for these centers, especially Central Asia, Middle East, Southwest China, India and Ethiopia. Regional differences in the world cancer prevalence is interesting (Figure 2; Figure 3), according to compared to the types of available foods specifically with anticancer activities. There are fivefold different for male incidence rates in the world, ranging from $0.79 \%$ in Western Africa to 3.65\% in Australia/New Zealand, but female incidence rates almost three-fold from $1.03 \%$ in South-Central Asia to $2.95 \%$ in Northern America (IARC, 2014). The mortality rates of men is the highest in Central and Eastern Europe $(1.73 \%$ ) and the lowest in Western Africa (0.69\%o), but the highest rates in women are in Melanesia (1.19\%o) and Eastern Africa $(1.11 \%$ ) , and the lowest in Central America $(0.72 \%)$ and South-Central Asia (0.65\%) (IARC, 2014).

\section{Functional Foods of Crop Origin Centers Associated with Human's Anticancer Activities}

The human species constitutes an integral part of organic evolution and the highest complexity (Ekstig, 2014) that associated with functional foods for anticancer crop. Specific dietary components can reduce the risk for cancer, cardiovascular disease and diabetes(Hardman, 2014). There are lower cancer incidence for Vavilov's eight centers of crop origin is in turn South America (1.95\%o, Peru-Ecuador-Bolivia, Southern Chile, and Southern Brazil $)>$ China- Korea $(1.88 \%$ ) $>$ Mediterranean $(1.75 \%$ o $)>$ Middle East $(1.70 \%$ ) $>$ South Asia $(1.42 \%$ o, e.g. Indo-Burma, Siam Malaya-Java) $>$ Ethiopia (1.40\%o) > Mexico-Guatemala (1.35\%o) > Southwest China (1.22\%o) $>$ Central Asia (1.05\%o) (IARC, 2014). There are lower cancer mortality for Vavilov's eight centers of crop origin is in turn Ethiopia $(1.10 \%$ ) $>$ Middle East $(1.08 \%$ ) $>$ South America $(1.04 \%$, Peru-Ecuador-Bolivia,Southern Chile, and Southern Brazil) $>$ China-Korea $(1.02 \%$ o $)>$ Mediterranean (0.96\%o) $>$ South Asia (0.95\%o, e.g. IndoBurma, Siam-Malaya-Java) $>$ Ethiopia $(0.78 \%$ o $)>$ Central Asia $(0.77 \%$ ) $>$ Mexico-Guatemala $(0.76 \%$ ) $>$ Yunnan Province of China $(0.54 \%$ ) (Zhou et al., 2010; IARC, 2014). Therefore, coevolution between cancer lower incidence and mortality worldwide in 2012 associated with major food for Vavilov's eight centers of crop origin (Wikipedia, 2013) is as follows (See Figure 2): 
Functional Foods Associated with Anticancer in Ethiopia $1=$ Ethiopia center: of crop origin includes Abyssinia, Eritrea and Somaliland. Both scapulae of Australopithecus afarensis from Ethiopia change significantly throughout modern human ontogeny, a substantial amount of climbing (Green et al., 2012), which is adapt to fruits for major food. The dietary flexibility of early hominins of Ethiopia in Africa to include consumption of foods (i.e. grasses, sedges, and succulents) represents a significant distinction between extant great apes and common ancestor (Wynn et al., 2013). Bitter taste perception for derived G-allele at $r s 702424$ in the TAS2R16 promoter has important roles in human health and nutrition, African diversity provides information of a biologically-relevant trait in humans (Campbell et al., 2014).

Ethiopia in Africa is not only top choice for cradle of modern humans (McDougall et al., 2005; Li et al., 2008), but also center of origin for 38 species in crop (Vavilov, 1951; Ladizinsky, 1998; Wikipedia, 2013),

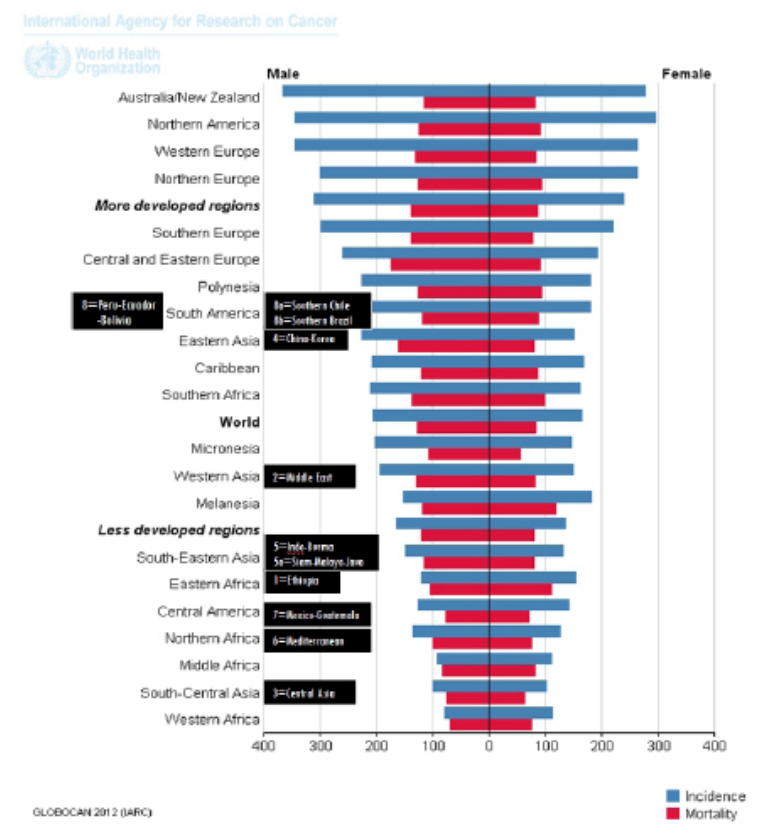

Figure 2. Estimated age-standardised rates per 100,000 for cancer in the world (IARC, 2014) and Vavilov's eight centers of crop origin (Ladizinsky, 1998)

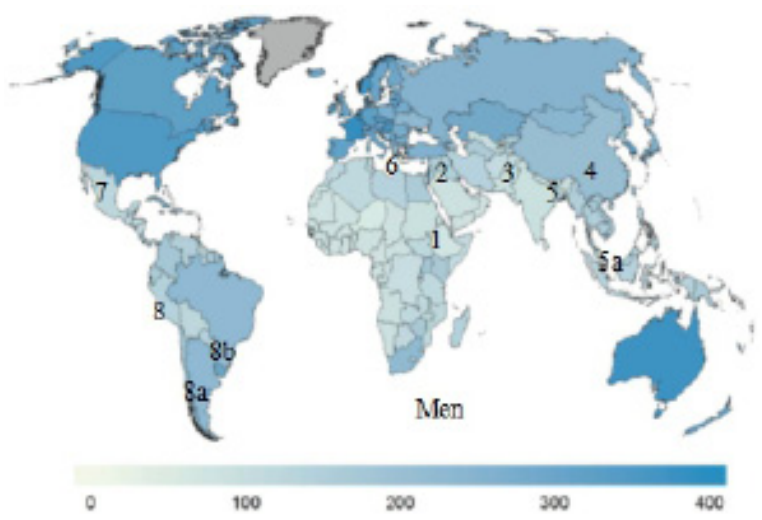

some functional foods with anticancer including to flax, garden cress, sesame, barley, coffee, castor bean (Mahassni, 2012; Lowcock et al., 2013; Zeng et al., 2013; Prado-Silva et al., 2014); Up to now, Ethiopia in Eastern Africa is major production region for these functional crop. Consumption of flaxseed and flax bread were was associated with a significant reduction in breast cancer risk (Lowcock et al., 2013). The aqueous extract of garden cress seeds is involved in apoptosis and is lacking in MCF-7 cells on breast cancer (Mahassni et al., 2012). The antioxidant compounds in sesame were beneficial to protect the mucosa against chemical carcinogenesis induced by 1, 2-dimethylhydrazine (Prado-Silva et al., 2014). Green barley extract has potential as an antileukemia/lymphoma agent alone or in combination with standard cancer therapies (Robles-Escajeda et al., 2013); the bioactive compounds for barley anticancer include $\beta$-Glucans, tocotrienols, poly-phenol, lunasin and so on. A modest protective effect for coffee plus tea in relation to early-onset basal cell carcinoma may be due to caffeine (Ferrucci et al., 2014). Flaxseed contents of $\alpha$-linolenic acid, lignans, and fiber, which have potential health benefits such as reduction of cancer,diabetes, osteoporosis, atherosclerosis, autoimmune, arthritis, cardiovascular disease, and neurological disorders (Goyal et al., 2014). Contemporary cancer incidence in Africa is the lowest in the world, i.e. Eastern Africa is $(1.40 \%$ o $)>$ Northern Africa $(1.33 \%$ ) $>$ Middle Africa $(1.02 \%$ ) $>$ Western Africa $(0.97 \%$ o $)$, but cancer mortality Northern Africa $(0.90 \%$ ) $>$ Middle Africa $(0.80 \%$ ) $>$ Eastern Africa $(0.78 \%$ ) $>$ Western Africa (0.73\%o). Therefore, functional foods for early and modern humans was associated with anticancer crop origin in Africa especially Ethiopia.

\section{Functional Foods Associated with Anticancer in Middle East}

2=Middle East: includes interior of Asia minor, all of Transcaucasia, Iran, and the highlands of Turkmenistan. Middle East is not only the cradle of civilization for modern humans (Fernandes et al., 2012; Witas et al., 2013 ) and about $70 \%$ of world's petroleum reserves, but also center of origin for 83 species in crop (Vavilov, 1951; Ladizinsky,1998), some functional foods with anticancer including to hawthorn, apple, cherry, barley, oats, and

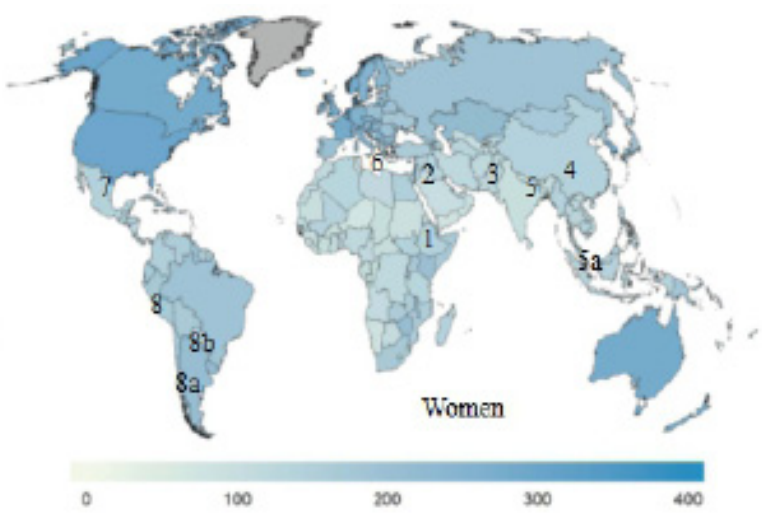

Figure 3. Estimated cancer incidence per 100,000 worldwide in 2012 (IARC, 2014) and Vavilov's eight centers of crop origin (Ladizinsky, 1998) 
pomegranate (Li et al., 2013; Zeng et al., 2013; Li et al., 2014; Ogur et al., 2014); Up to now, Middle East is major production region for these functional crop. The anticancer effects of polyphenolic extract from hawthorn fruit in human MCF-7 breast cancer cells, which is an excellent source of natural chemopreventive agents in the treatment of breast cancer ( $\mathrm{Li}$ et al., 2013). Apple oligogalactan could potentiate the growth inhibitory effect of celecoxib on colorectal cancer through influencing the expression and function of cyclooxygenase- 2 and phosphorylation of MAPKs, which suggests a new possible combinatorial strategy in colorectal cancer therapy (Li et al., 2014). Cherry is popular preserve in Turkish cuisine, its consumption may decrease the risk of cancer and chronic diseases (Ogur et al., 2014). Protocatechualdehyde from the root of the herb S. miltiorrhiza and barley tea plants possesses antiproliferative and pro-apoptotic properties in human colorectal cancer cells (Choi et al., 2014). The elucidating the molecular mechanisms of $\beta$-glucaninduced signaling in immune cells is essential for the design of new therapeutic strategies against cancer in oat, barley and so on (Albeituni et al., 2013). Conjugated linolenic acids as the major components of the hydrophilic fraction from pomegranate (Punica granatum L.) seed oil have anti-inflammatory and anti-oxidant potential on breast cancer lines (Costantini et al., 2014). Contemporary cancer incidence (1.70\%) and mortality (1.08\%o) in Middle East is lower in the world. Therefore, functional foods for early and modern humans was associated with anticancer crop origin in Middle East.

\section{Functional Foods Associated with Anticancer in Central Asia}

$\underline{3}=$ Central Asiatic Center: for core region of the Asian continent includes Northwest India (Punjab and Kashmir), Afghanistan, Tajikistan, Uzbekistan and western TianShan. Central Asia is not only located on the Silk Road and a corridor for human migrations (Lacau et al., 2012), but also center of origin for 43 species in Crop (Vavilov, 1951; Ladizinsky,1998; Wikipedia, 2013), some functional foods with anticancer including to grape, mung bean, spinach, carrot, onion, garlic, mustard, apple, flax, and sesame (Lowcock et al., 2013; Maeda et al., 2013; Zeng et al., 2013; Cheah et al., 2014; Li et al., 2014; Li et al., 2014; Prado-Silva et al., 2014; Xu et al., 2014); Up to now, Central Asia is major production region for these functional crop. Grape seed procyanidins not only enhanced the impact of 5-Fluorouracil in killing colon cancer cells, but also surpassed standard 5-Fluorouracil chemotherapy as an anticancer agent (Cheah et al., 2014). The fusion protein with mung bean trypsin may be developed as a therapeutic agent for colon cancer, and holds important implications for developing other anticancer peptide drugs (Li et al., 2014). Mono-galactosyl diacylglycerol from spinach suppressed the proliferation of colon cancer cells, which has the potential for cancer prevention and health promotion (Maeda et al., 2013). Carrot intake might be inversely associated with prostate cancer risk (Xu et al., 2014). Compounds in onions have been reported with lots of health benefits, including anticancer, antiplatelet, antithrombotic, anti-asthmatic, and antibiotic effects (Suleria et al., 2015). Diallyl disulfide from garlic has the potential to be an effective and safe anticancer agent for esophageal squamous cell carcinoma therapy (Yin et al., 2014). Allyl isothiocyanate in mustard seed has been considered a antineoplastic agent against bladder cancer (Savio et al., 2014). Contemporary cancer incidence (1.05\%o) and mortality $(0.77 \%$ ) in Central Asia is the lowest in the world. Therefore, functional foods for early and modern humans was associated with anticancer crop origin in Central Asia.

\section{Functional Foods Associated with Anticancer in China and Korea}

4=China-Korea Center: is not only the cradle of civilization for modern humans, but also center of origin for 136 species in crop (Vavilov, 1951; Ladizinsky, 1998; Wikipedia, 2013), some functional foods with anticancer including to rice, buckwheat, tea, millet, soybean, adzuki bean,Chinese yam, radish, onion, cucumber, Chinese apple, peach, apricot, walnut, litchi, hemp, cabbage, hullless barley and cherry (Miyoshi et al., 2011; Huang et al., 2012; Hsu et al., 2012; Xu et al., 2012; Hattori et al., 2013; Zeng et al., 2013; Zhang et al., 2013; Benyamina, 2014; Gao et al., 2014; Ghoneum et al., 2014; Hardman, 2014; Li et al., 2014; Ogur et al., 2014; Panda et al., 2014; Shan et al., 2014; Vizzotto et al., 2014; Wang et al., 2014; Hajiaghaalipour et al., 2015). Up to now, China especially Yunnan province is major production region for these functional crop. Rice is one of the most important cereal for human nutrition (Huang et al., 2012) and contributes $21 \%$ to human's nutrient intake and energy requirements; Arabinoxylan from rice bran may represent a novel adjuvant for the treatment of breast cancer (Ghoneum et al., 2014). The antioxidant capacity of quercetin from tartary buckwheat seeds and bran was the induction of G2/M arrest, apoptosis, however cell death by quercetin may associate with increased expression of p53 and p21, decrease of Cyclin D1, Cdk2, and Cdk7 levels (Li et al., 2014). White tea has antioxidant and antiproliferative effects against cancer cells, but protect normal cells against DNA damage (Hajiaghaalipour et al., 2015). Foxtail millet bran is able to suppress colon cancer cell growth and also causes a loss of mitochondrial transmembrane potential which results in caspase-dependent apoptosis in colon cancer cells (Shan et al., 2014).Apoptotic, autophagic death, and DNA-damaging effects of soybean lectin's in cancer cells may have the potential to be used as a phytoderived protein for cancer therapy (Panda et al., 2014). Adzuki bean exhibited the strongest antiproliferative properties in a dose-dependent manner against all digestive system, ovary and breast cancer cell lines (Xu et al., 2012). Chinese yams could be ingested to prevent colon carcinogenesis in humans (Miyoshi et al., 2011). Mitochondrial pathway and $\mathrm{Bcl}-2$ gene family could be involved in the mechanisms of A549 cell apoptosis induced by 4-Methylsulfinyl-3-butenyl isothiocyanate in radish (Raphanus sativus L.), which is a well-known anti-cancer agent (Wang et al., 2014). Cucurbitacin B is found abundantly in cucumbers, a novel anti-tumor mechanism of Cucurbitacin B via inhibition of ACYL signaling in human cancer (Gao et al., 2014). Modified 
apple poly-saccharides suppressed LPS-induced migration and invasiveness of colorectal cancer cells by targeting the LPS/TLR4/NF- $x$ B pathway (Zhang et al., 2013). Polyphenolic extracts and fractions of selected peach and plum genotypes can be added to the list of fruits with cytotoxic effects against breastcancer cells while not affecting normal cells (Vizzotto et al., 2014). MK615 from Japanese apricot may have therapeutic value in treating human cancers (Hattori et al., 2013). Part of the mechanism for the anticancer benefit of walnut was by suppressing the activation of NFxB (Hardman, 2014). The pericarp of the Litchi fruit has been shown to inhibit breast and liver as well as colorectal cancer cell growth, based on rich amounts of its flavanoids and proanthocyanidins (Hsu et al., 2012). Cannabinoids from hemp such as dronabinol, Sativex and nabilone are most promising to relieve chronic pain associated with cancer, human immunodeficiency virus infection and multiple sclerosis (Benyamina, 2014). Contemporary cancer incidence $(1.88 \%$ ) and mortality $(1.02 \%$ ) in China is lower in the world, i.e Eastern Asia. Therefore, abundantly functional foods for early and modern humans was associated with anticancer crop origin in China and Korea.

\section{Functional Foods Associated with Anticancer in India}

5=Indo-Burma: for main center includes Assam in India and Burma, some functional foods with anticancer including to mango, orange, tangerine, tamarind, safflower, black pepper, bamboo, rice, mung bean, cucumber, yam, radish,sesame and hemp (Seki et al., 2010; Miyoshi et al., 2011; Xi et al., 2012; Zeng et al., 2013; Abdullah et al., 2014; Benyamina 2014; Gao et al., 2014; Genovese et al., 2014; Joseph et al., 2014; Li et al., 2014; PradoSilva et al., 2014; Wang et al., 2014; Yaffe et al., 2014); Up to now, Indo-Burma is major production region for these functional crop. The extract of waterlily mango (Mangifera indica L.) has potential activity against breast cancer cells (Abdullah et al., 2014). 4'-Geranyloxyferulic and boropinic acid having valuable pharmacological effects as cancer chemopreventive, and so on agents, but the richest in 4'-Geranyloxyferulic of exocarp fresh weight of orange $(0.141 \pm 0.011 \mathrm{mg} / \mathrm{g})$ and boropinic acid of exocarp fresh weight of kumquat $(0.206 \pm 0.002$ $\mathrm{mg} / \mathrm{g}$ ) (Genovese et al., 2014). Galactoxyloglucan-gold nanoparticles from the seed kernels of Tamarindus indica not only retained the anticancer effects of PST001, but also showed enhanced cytotoxicity via induction of apoptosis even at lower doses and lesser incubation times (Joseph et al., 2014). Hydroxy safflower yellow-A inhibits the growth of transplanted BGC-823 tumors, and its effects on tumor capillary angiogenesis (Xi et al., 2012). Piperine for the treatment of colon cancer is a piperidine alkaloid present in black pepper, cell cycle arrest and endoplasmic reticulum stress-associated apoptosis following piperine treatment of HT-29 cells (Yaffe et al., 2014). The vigorous extracts of bamboo leaf show immunopotentiating and radical scavenging effects and administration prior to carcinogen exposure or tumor inoculation significantly suppresses tumor incidence and tumor growth and prolongs survival (Seki et al., 2010).

$\underline{5 a}=$ Siam-Malaya-Java: includes Indo-China and the
Malay Archipelago, some functional foods with anticancer including to mangosteen, clove, nutmeg, black pepper (Jittiporn et al., 2014; Sultana et al., 2014; Thuong et al., 2014; Yaffe et al., 2014). $\alpha$-Mangostin in mangosteen has been shown to have an anti-oxidant property involving angiogenesis such as cancer (Jittiporn et al., 2014). Clove seed extract exhibited an appreciable amount of total phenolics for the development of chemotherapeutic drugs against cancer and functional food ingredient (Sultana et al., 2014). Meso-dihydroguaiaretic acid in the seeds of Myristica fragrans exhibited potent cytotoxicity against H358 for antitumor activity (Thuong et al., 2014).

In all word, Indian Center is not only the cradle of civilization for modern humans (Witas et al., 2013), but also center of origin for 117 species in crop for Indo -Burma and 55 species in crop for Siam-Malaya-Java (Vavilov, 1951; Ladizinsky, 1998); Up to now, Indian Center is major production region for these functional crop. Contemporary cancer incidence $(1.42 \%$ ) and mortality $(0.95 \%$ ) in South-Eastern Asia is lower in the world. Therefore, functional foods for early and modern humans was associated with anticancer crop origin in Indian Center.

\section{Functional Foods Associated with Anticancer in Mediterranean}

6=Mediterranean Center: includes the borders of the Mediterranean Sea, which is not only the cradle of Mediterranean diet for disease prevention for modern humans, but also center of origin for 84 species in crop (Vavilov, 1951; Ladizinsky, 1998; Wikipedia, 2013), some functional foods with anticancer including to olive, turnip, asparagus, celery, rhubarb, caraway, oats, flax, and cabbage (Lowcock et al., 2013; Shiezadeh et al., 2013; Wu et al., 2013; Zeng et al., 2013; Akl et al., 2014; Quassinti et al., 2014; Sutton et al., 2014; Xiang et al., 2014); Up to now, Mediterranean Center is major production region for these functional crop. (-)- Oleocanthal from extra virgin olive oil showed antiproliferative and antimigratory activity against different cancer cell lines (Akl et al., 2014). All compounds in turnip exhibited high inhibitory activity against the growth of human cancer lines (Wu et al., 2013). Deproteinized asparagus polysaccharide exhibited significant anticancer activity, indicating that it is a potential therapeutic agent for liver cancer therapy (Xiang et al., 2014). Wild celery oil and isofuranodiene are able to induce apoptosis in colon cancer cells in a time and concentration-dependent manner suggesting a potential role as models for the development of chemopreventive agents (Quassinti et al., 2014). People use roots of rhubarb (R. Turkestanicum) as an anticancer, anti-diabetic and anti-hypertensive agent (Shiezadeh et al., 2013). Thymoquinone from black caraway seeds has several anticancer activities, which it could be useful in the management of triple- negative breast cancer, based on thymoquinone-induced apoptosis was partially inhibited by zVAD-fmk (Sutton et al., 2014). Contemporary cancer incidence $(1.34 \%$ ) and mortality $(0.88 \%$ ) in Northern Africa.Therefore, functional foods for early and modern humans was associated with anticancer crop origin in Mediterranean Center. 
Functional Foods Associated with Anticancer in Mexico -Guatemala

7=Mexico-Guatemala Center: include southern sections of Mexico, Guatemala, Honduras and Costa Rica, which is not only great ethnic diversity of modern humans (Melton et al., 2013; Moreno-Estrada et al., 2014), but also center of origin for maize and so on 22 species in crop (Vavilov, 1951;Ladizinsky, 1998), some functional foods with anticancer including to common beans, tepary bean, pepper, papaya, guava, cocoa, and cherry (Garcia-Gasca et al., 2012; Latif, 2013; Feregrino-Perez et al., 2014; Ogur et al., 2014; Pathak et al., 2014; Rizzo et al., 2014; Yaffe et al., 2014).Up to now, Central America is major production region for these functional crop. Nondigestible fraction of cooked common beans inhibited colon carcinogenesis at an early stage by inducing cell cycle arrest of colon cells and morphological changes linked to apoptosis (FeregrinoPerez et al., 2014). Tepary bean seeds contain at least 2 different groups of bioactive proteins with distinct effects on cancer cells (Garcia-Gasca et al., 2012).The cancer chemopreventive potential of a flavonoidrich fraction isolated from the seeds of Carica papaya, however, the inverse association between dietary flavonoid intake and cancer risk (Pathak et al., 2014). The guava extracts reduce tumor growth and stimulate uterus proliferation, as well as their in silico docking similarity to tamoxifen, therefore holding significant potential for anticancer therapy (Rizzo et al., 2014). Cocoa may have the potential to be used for the prevention/treatment of cancers, allergies, oxidative injuries, anxiety, inflammatory conditions, hyperglycemia, and insulin resistance (Latif, 2013). Contemporary cancer incidence $(1.35 \%$ ) and mortality $(0.75 \%$ ) in Central America. Therefore, functional foods for early and modern humans was associated with anticancer crop origin in Mexico-Guatemala Center.

\section{Functional Foods Associated with Anticancer in South} America

8=South American Center: for three subcenters (Peru-Ecuador-Bolivia, 8; Southern Chile, 8a; Southern Brazil, 8 b) is not only the one biodiversity hotspot in the world, but also center of origin for 62 species in crop (Vavilov, 1951; Ladizinsky, 1998; Wikipedia, 2013), some functional foods with anticancer including to tomato, peanut, pineapple, common beans, pumpkin, pepper, cocoa, and guava (Chen et al., 2013; Latif, 2013; Richter et al., 2013; Feregrino-Perez et al., 2014; Mukhopadhyay et al., 2014; Rizzo et al., 2014; Romano et al., 2014; Yaffe et al., 2014); Up to now, South America is major production region for these functional crop. Tomato may play a modest role in the prevention of prostate cancer (Chen et al., 2013). Pumpkin seed's lignans has a potential role in the prevention and/or treatment of breast cancer (Richter et al., 2013). Peanut agglutinin was for the first time evaluated mechanistically in vivo and in vitro as a novel naturally occurring therapeutic agent against cancer (Mukhopadhyay et al., 2014). Bromelain from the pineapple stem exerts antiproliferative and proapoptotic effects in colorectal carcinoma cells and chemopreventive actions in colon carcinogenesis in vivo (Romano et al., 2014). Contemporary cancer incidence (1.95\%o) and mortality $(1.04 \%$ ) in South America is lower in the world. Therefore, functional foods for early and modern humans was associated with anticancer crop origin in South American Center.

\section{Asians Anticancer Activities and Functional Foods}

Southwest China is the cradle of human childhood

Southwest China includes Yunnan, Guizhou, and Sichuan province, the municipality of Chongqing, and the Tibet Autonomous Region. The early modern human of Southwest China was related to many ancestors of Asians. The fossil ape Lufengpithecus at late Miocene sites in Yunnan Province reveals a morphological pattern largely consistent with a stem member of the hominid clade (Kelley et al., 2014). Yuanmou hominins of Southwest China lived in a varied habitat of open vegetation with patches of bushland and forest on an alluvial fan close to a lake or swamp in 1700 kya, which are consistent with a rapid southern migration route of initial hominin populations into Eastern Asia (Zhu et al., 2008). The morphology sampled at Longlin Cave (Guangxi Province) and Maludong (Yunnan Province) of Southwest China may represent a paralleling the situation seen in North Africa as indicated by remains from Dar-es-Soltane and Temara, based on ancient mtDNA and Y-DNA lineages, and has yielded a number of human remains thought to derive from Pleistocene deposits (Curnoe et al., 2012). Myanmar haplogroup distribution showed a typical Southeast Asian pattern, but also Northeast Asian and Indian influences (Summerer et al., 2014). Andaman archipelago was settled by modern humans from northeast India via the landbridge which connected the Andaman archipelago and Myanmar around the Last Glacial Maximum (Wang et al.. 2011). The intensifying human activity and land-use were associated with Xingyun's catchment in central Yunnan, which provide a record of environmental history since the Holocene (Zhang et al., 2014a). The average genetic heterogeneity in ten minorities was above 0.7 , however, the gene flow of Yi and Dai minorities were higher than that of other minorities, while the pattern of gene flow of Dulong minority demonstrated some of the isolation (Kuang et al., 2011).

Humans is the adaptation of Tibetans to the hypoxic environment of the world's highest Tibetan plateau, which the selected haplotype is found in Denisovans and in Tibetans, and at very low frequency among Han Chinese (Huerta-Sanchez et al., 2014). People inhabiting today's Tibet in China, Himalayas, India and Pakistan, which may have been descendants of migrants from much earlier times, spreading the clades of the macrohaplo group $\mathrm{M}$ throughout Eurasia and founding regional Mesopotamian groups like that of merchants moving along trade routes passing the region (Witas et al., 2013). A remarkable genetic differentiation between the Tibeto-Burman and Indo-European, which suggesting that language and geography have played an equally large role in defining the genetic composition of present-day populations within the Himalayas (Kraaijenbrink et al., 2014). Mutational changes in p53 correlate well with 
tumorigenesis, but codon 104 variation of p53 are an outcome of environmental adaptation and evolutionary selection for hypoxia and cold and hypercapnia in the stressful environments of the Qinghai-Tibet plateau (Zhao et al., 2013).Tibetans have been adapted to a high altitude environment since initial colonization of the Tibetan Plateau in the early Upper Paleolithic approximately 30 kya (Qi et al., 2013).

The hominid teeth and evidence of hominid activities from Panxian Dadong site in Guizhou Province of Southwest China are dated to the late Middle Pleistocene (130-300 kya), and they highlight the necessity of incorporating the Asian fossil record in the origin of H. Sapiens (Liu et al., 2013b). The majority of Miaos, Bouyeis, and Shuis are distributed in the Guizhou province of Southwest China, although it appears that some alleles distribute ethnic-specifically for each ethnicity, but three genetically close ethnic groups and inherit more characteristics of southern Chinese populations (Chen et al., 2007).

\section{Asians Anticancer Activities and Functional Foods for Origin Crop}

Cancer prevention of early human migrations was associated with functional foods from crop origin centers, especially Asia with four centers of crop origin, which accounting for $58 \%$ in the world populations. Asia is not only the cradle of civilization for modern humans such as China, Middle East and India (Witas et al., 2013) as well as a corridor for human migrations such as Central Asia (Lacau et al., 2012), but also is the lowest mortality and incidence of cancers in world, especially Central Southern Asia, Western Asia, South Eastern Asia and Eastern Asia. Asia is center of the richest in crop origin and anticancer crop, which was center of origin for 379 species in crop and over 40 species in anticancer crop, it includes four centers and one subcenter of crop origin i.e. China-Korea, Middle East, Central Asia, Indo-Burma, and Siam-Malaya-Java. Southwest China with the richest in anticancer crop is the lowest mortality and incidence of cancers in China (Zhou et al., 2010; Zeng et al., 2013).

\section{Africans Anticancer Activities and Functional Foods}

\section{Africa is geographic origin of human being}

Out of Africa theory is the most widely accepted model of the geographic origin and early migration of modern humans (Stewart et al., 2012), but they encountered many new environmental conditions, including higher altitudes, greater temperature extremes and different pathogens, (Huerta-Sanchez et al., 2014), and food structure (See Figure 1). Modern humans originated from an ancestral African population between $\sim 100-200 \mathrm{ka}$, but an initial dispersal into Asia by a southern route beginning as early as $\sim 130 \mathrm{ka}$ and a later dispersal into northern Eurasia by $\sim 50 \mathrm{ka}$ (Reyes-Centeno et al., 2014). African's migrations and interaction starting about $100 \mathrm{kya}$, and the adoption of a new refugium by a subgroup of a species may lead to important evolutionary changes (Stewart et al., 2012). A great demic expansion that began approximately 45 to
60 kya in Africa and rapidly resulted in human occupation of almost all of the Earth's habitable regions (Henn et al., 2012).

\section{Africans anticancer activities and functional foods for origin crop}

Cancer prevention of early human migrations was associated with functional foods from crop origin centers, especially Ethiopia. Africa is not only origin center of humans, but also is the lowest mortality and incidence of cancers in world, especially western and middle Africa; Ethiopia in Africa is not only top choice for cradle of modern humans, but also center of origin for 38 species in crop and over 6 species in anticancer crop. In addition, people with white skin are about 70 times more likely to develop skin cancer than that of black skin (Greaves, 2014).

\section{Conclusions and Perspectives}

Cancer is expected to be the leading cause of death around the world. This article describes correlation between cancer prevalence and types of food with anticancer activities from crop origin center in the world as well as food source with human migration. The correlation of cancer prevalence and types of food source are worth examining. Hunger for food shortage is the cause of early humans evolution from Africa to Asia and later into Eurasia. There are the most richest in food types in Vavilov's eight crop origin centers, which has been the best survival regions of early humans migration and modern humans about $70 \%$ in the world populations. We suggest not only that coevolution between anticancer activities of humans associated with major functional foods for Vavilov's eight centers of anticancer crop origin, but also there are lower cancer incidence and mortality for these anticancer crop centers, especially Central Asia, Middle East, Southwest China, India and Ethiopia. The early modern human of Southwest China was related to many ancestors of Asians. Asia with the richest in anticancer crop is not only the most important evolution base of human being and anticancer functional foods for origin crop, but also is the lowest mortality and incidence of cancers in world, especially Central Southern Asia, Western Asia, South Eastern Asia and Eastern Asia. Cancer prevention of early human migrations was associated with functional foods from crop origin centers, especially Asia with four centers of crop origin, which accounting for $58 \%$ in the world populations. Africa is not only origin center of humans, but also is the lowest incidence and mortality of cancers in world, especially western and middle Africa; Ethiopia is top choice for cradle of modern humans and center of origin for 38 species in crop as well as over 6 species in anticancer crop. In addition, latest researches indicate functional foods for cancer prevention from crop origin center in the world is not only similar to heart disease and hypertension as well as diabetes prevention in the world, but also associated with functional foods structure and so on, which their inner connection needs further investigation. 


\section{Acknowledgements}

This research is supported by the National Natural Science Foundation of China (No.31260326), China Agriculture Research System (CARS-05), the Science and Technology to Benefit the People (2014RA060) from Yunnan Provincial Scientific and Technology Department.

\section{References}

Abdullah AS, Mohammed AS, Abdullah R, et al (2014). Cytotoxic effects of Mangifera indica L. kernel extract on human breast cancer (MCF-7 and MDA-MB-231 cell lines) and bioactive constituents in the crude extract. $B M C$ Complement Altern Med, 14, 199.

Akl MR, Ayoub NM, Mohyeldin MM, et al (2014). Olive phenolics as c-Met inhibitors: (-)- Oleocanthal attenuates cell proliferation, invasiveness, and tumor growth in breast cancer models. PLoS One, 9, 97622.

Albeituni SH, Yan J (2013). The effects of $\beta$-glucans on dendritic cells and implications for cancer therapy. Anticancer Agents Med Chem, 13, 689-98.

Benyamina A, Reynaud M (2014). Therapeutic use of cannabis derivatives. Rev Prat, 64, 165-8.

Bozek K, Wei Y, Yan Z, et al (2014). Exceptional evolutionary divergence of human muscle and brain metabolomes parallels human cognitive and physical uniqueness. PLoS Biol, 12, 1001871.

Burenhult G (2000). Die ersten Menschen, Weltbild Verlag, ISBN 3-8289-0741-5.

Burunat E (2014). Love is the cause of human evolution. $A d v$ Anthropol, 4, 99-116.

Campbell MC, Ranciaro A, Zinshteyn D, et al (2014). Limited evidence for adaptive evolution and functional effect of allelic variation at rs702424 in the promoter of the TAS2R 16 bitter taste receptor gene in Africa. J Hum Genet, 59, 349-52.

Casto AM, Henn BM, Kidd JM, et al (2012). A tale of two haplotypes: the EDA2R/AR Intergenic region is the most divergent genomic segment between Africans and East Asians in the human genome. Hum Biol, 84, 641- 94.

Cheah KY, Howarth GS, Bindon KA, et al (2014). Low molecular weight procyanidins from grape seeds enhance the impact of 5- Fluorouracil chemotherapy on Caco-2 human colon cancer cells. PLoS One, 9, 98921.

Chen J, Song Y, Zhang L (2013). Lycopene / tomato consumption and the risk of prostate cancer: a systematic review and meta-analysis of prospective studies. J Nutr Sci Vitaminol, 59, 213-23.

Chen S, Ren X, Liu Y, et al (2007). Human leukocyte antigen class i polymorphism in miao, bouyei, and shui ethnic minorities of Guizhou, China. Hum Immunol, 68, 928-33.

Choi J, Jiang X, Jeong JB, et al (2014). Anticancer activity of protocatechualdehyde in human breast cancer cells. J Med Food, 17, 842-48.

Costantini S, Rusolo F, De Vito, et al (2014). Potential anti- inflammatory effects of the hydrophilic fraction of pomegranate (Punica granatum L.) seed oil on breast cancer cell lines. Molecules, 19, 8644-60.

Curnoe D, Ji XP, Herries AI, et al (2012). Human remains from the pleistocene-holocene transition of Southwest China suggest a complex evolutionary history for east Asians. PLOS ONE, 7, 31918.

Ekstig B (2014). Complexity, natural selection and the evolution of life and humans. Found Sci, doi:10.1007/S10699-0149358-y.

Feregrino-Perez AA, Pinol-Felis C, Gomez-Arbones, et al
(2014). A non-digestible fraction of the common bean (Phaseolus vulgaris L.) induces cell cycle arrest and apoptosis during early carcinogenesis. Plant Foods Hum Nutr, 69, 248-54.

Fernandes V, Alshamali F, Alves M, et al (2012). The Arabian cradle: mitochondrial relicts of the first steps along the southern route out of Africa. Am J Hum Genet, 90, 347-55.

Ferrucci LM, Cartmel B, Molinaro AM, et al (2014). Tea, coffee, and caffeine and early-onset basal cell carcinoma in a casecontrol study. Eur J Cancer Prev, 23, 296-302.

Fu JS, Chen HD, Soroka DN, et al (2014). Cysteine- conjugated metabolites of ginger components, shogaols, induce apoptosis through oxidative stress-mediated 553 pathway in human colon cancer cells. J Agric Food Chem, 62, 4632-42.

Gao Y, Islam MS, Tian J, et al (2014). Inactivation of ATP citrate lyase by cucurbitacin b: a bioactive compound from cucumber, inhibits prostate cancer growth. Cancer Lett, 349, 15-25.

Garcia-Gasca T, Garcia-Cruz M, Hernandez-Rivera E, et al (2012). Effects of Tepary bean (phaseolus acutifolius) protease inhibitor and semipure lectin fractions on cancer cells. Nutr Cancer, 64, 1269-78.

Genovese S, Fiorito S, Locatelli M, et al (2014). Analysis of biologically active oxyprenylated ferulic acid derivatives in citrus fruits. Plant Foods Hum Nutr, 69, 255-60.

Ghoneum M, Badr El-Din NK, Ali DA, et al (2014). Modified arabinoxylan from rice bran, MGN-3/biobran, sensitizes metastatic breast cancer cells to paclitaxel in vitro. Anticancer Res, 34, 81-7.

Goyal A, Sharma V, Upadhyay N, et al (2014). Flax and flaxseed oil: an ancient medicine and modern functional food. J Food Sci Technol, 59, 1633-53.

Greaves M (2014). Was skin cancer a selective force for black pigmentation in early hominin evolution? Proc $R$ Soc B, 281, 20132955.

Green DJ, Alemseged Z (2012). Australopithecus afarensis scapular ontogeny, function, and the role of climbing inhuman evolution. Science, 338, 514-7.

Hajiaghaalipour F, Kanthimathi MS, Sanusi J, et al (2015). White tea (Camellia sinensis) inhibits proliferation of the colon cancer cell line, HT-29, activates caspases and protects DNA of normal cells against oxidative damage. Food Chem, 169, 401-10.

Hardman WE (2014). Diet components can suppress inflammation and reduce cancer risk. Nutr Res Pract, 8, 233-40.

Hattori M, Kawakami K, Akimoto M, et al (2013). Antitumor effect of Japanese apricot extract (MK615) on human cancer cells in vitro and in vivo through a reactive oxygen speciesdependent mechanism. Tumori, 99, 239-48.

Henn BM, Cavalli-Sforza LL, Feldman MW (2012). The great human expansion. Proc Natl Acad Sci USA, 109, 17758-64.

Henry AG, Brooks AS, Piperno DR (2014). Plant foods and the dietary ecology of Neanderthals and early modern humans. J Human Evol, 69, 44-54.

Huang XH, KurataN, Wei XH, et al (2012). A map of rice genome variation reveals the origin of cultivated rice. Nature, $\mathbf{4 9 0}$, 497-501.

Khrameeva EE, Bozek K, He L, et al (2014). Neanderthal ancestry drives evolution of lipid catabolism in contemporary Europeans. Nature Commun, 5, 3584.

Hsu CP, Lin CC, Huang CC, et al (2012). Induction of apoptosis and cell cycle arrest in human colorectal carcinoma by Litchi seed extract. J Biomed Biotechnol, 2012, 341479.

Huerta-Sanchez E, Jin X, Asan Bianba, et al (2014). Altitude adaptation in Tibetans caused by introgression of Denisovanlike DNA. Nature, 512, 194-7.

International Agency for Research on Cancer (IARC) (2014). 
Estimated Incidence, mortality and prevalence worldwide in 2012. Available from: http://globocan. iarc.fr/old/FactSheets/ cancers/all-new.asp\#TOP,access date 04/10/2014.

Jittiporn K, Suwanpradid J, Patel C, et al (2014). Anti- angiogenic actions of the mangosteen polyphenolic xanthone derivative $\alpha$-mangostin. Microvasc Res, 93, 72-9.

Joseph MM, Aravind SR,George SK, et al (2014). Anti- tumor activity of galactoxyloglucan-gold nanoparticles against murine ascites and solid carcinoma. Colloids Surf B: Biointerfaces, 116, 219-27.

Kelley J, Gao F (2012). Juvenile hominoid cranium from the late miocene of southern China and hominoid diversity in Asia. Proc Natl Acad Sci USA, 109, 6882-5.

Kraaijenbrink T, van der Gaag KJ, Zuniga SB, et al (2014). A linguistically informed autosomal STR survey of human populations residing in the greater Himalayan region. PLOS One, 9, 91534.

Kuang WJ, Huang P, Tuo Y, et al (2011). Genetic differentiation and patterns of gene flow of ten minorities in Yunnan province. J Forensic Med, 27, 112-6.

Lacau H, Gayden T, Regueiro M, et al (2012). Afghanistan from a Y-chromosome perspective. Eur J Hum Genet, 20, 1063-70.

Ladizinsky G (1998). Plant evolution under domestication. the netherlands: kluwer academic publishers.

Latif R (2013). Health benefits of cocoa. Curr Opin Clin Nutr Metab Care, 16, 669-74.

Li JZ, Absher DM, Tang H, et al (2008). Worldwide human relationships inferred from genome-wide patterns of variation. Science, 319, 1100-4.

Li T, Zhu J, Guo L, et al (2013). Differential effects of polyphenols-enriched extracts from hawthorn fruit peels and fleshes on cell cycle and apoptosis in human MCF-7 breast carcinoma cells. Food Chem, 141, 1008 -18.

Li Y, Duan S, Jia H, et al (2014). Flavonoids from tartary buckwheat induce G2/M cell cycle arrest and apoptosis in human hepatoma HepG2 cells. Acta Biochim Biophys Sin, 46, 460-70.

Li Y, Niu Y, Sun Y, et al (2014). An apple oligogalactan potentiates the growth inhibitory effect of celecoxib on colorectal cancer. Nutr Cancer, 66, 29-37.

Li Y, Qian YP, Yu XJ, et al (2004). Recent origin of a hominoidspecific splice form of neuropsin, a gene involved in learning and memory. Mol Biol Evol, 21, 2111-5.

Li Z, Zhao C, Li Z, et al (2014). Reconstructed mung bean trypsin inhibitor targeting cell surface GRP78 induces apoptosis and inhibits tumor growth in colorectal cancer. Int J Biochem Cell Biol, 47, 68-75.

Liu W, Schepartz LA, Xing S, et al (2013). Late middle pleistocene hominin teeth from Panxian Dadong, South China. J Hum Evol, 64, 337-55.

Lordkipanidze D, Ponce de Leon MS, Margvelashvili A, et al (2013). A complete skull from Dmanisi, Georgia, and the evolutionary biology of early Homo. Science, 342, 326-31.

Lowcock EC, Cotterchio M, Boucher BA (2013). Consumption of flaxseed, a rich source of lignans, is associated with reduced breast cancer risk. Cancer Causes Control, 24, 813-6.

Lucci P, Pacetti D, Loizzo MR, et al (2015). Punica granatum cv. dente di cavallo seed ethanolic extract: antioxidant and antiproliferative activities. Food Chem, 167, 475-83.

Luo LP,Han B,Yu XP, et al (2014). Anti-metastasis activity of black rice anthocyanins against breast cancer: analyses using an ErbB2 positive breast cancer cell line and tumoral xenograft model. Asian Pac J Cancer Prev, 15, 6219-25.

Maeda N,Kokai Y, Hada, T, et al (2013). Oral administration of monogalactosyl diacylglycerol from spinach inhibits colon tumor growth in mice. Exp Ther Med, 5, 17-22.
Mahassni SH,Al-Reemi RM(2013). Apoptosis and necrosis of human breast cancer cells by an aqueous extract of garden cress (Lepidium sativum) seeds. Saudi J Biol Sci, 20, 131-9.

McDougall I, Brown FH, Fleagle JG (2005). Stratigraphic placement and age of modern humans from Kibish, Ethiopia. Nature, 433, 733-6.

Melton PE, Baldi NF, Barrantes R, et al (2013). Micro- evolution, migration, and the population structure of five amerindian populations from nicaragua and costa rica. Am J Hum Biol, 25, 480-90.

Miyoshi N, Nagasawa T, Mabuchi R, et al (2011). Chemoprevention of azoxymethane/dextran sodium sulfateinduced mouse colon carcinogenesis by freeze- dried yam sanyaku and its constituent diosgenin. Cancer Prev Res (Phila), 4, 924-34.

Moreno-Estrada A, Gignoux CR, Fernandez-Lopez JC, et al (2014). The genetics of Mexico recapitulates Native American substructure and affects biomedical traits. Science, 344, 1280-5.

Mukhopadhyay S, Panda PK, Behera B, et al (2014). In vitro and in vivo antitumor effects of Peanut agglutinin through induction of apoptotic and autophagic cell death. Food Chem Toxicol, 64, 369-77.

Ogur R, Istanbulluoglu H, Korkmaz A, et al (2014). Report: investigation of anti-cancer effects of cherry in vitro. Pak J Pharm Sci, 27, 587-92.

Olalde I, Allentoft ME, et al (2014). Derived immune and ancestral pigmentation alleles in a 7,000-year-old mesolithic European. Nature, 507, 225-8.

Panda PK,Mukhopadhyay S, Behera B, et al (2014). Anti- tumor effect of soybean lectin mediated through a reactive oxygen species-dependent pathway. Life Sci, 111, 27-35.

Pathak N, Khan S, Bhargava A, et al (2014). Cancer chemopreventive effects of the flavonoid-rich fraction isolated from papaya seeds. Nutr Cancer, 66, 857-71.

Prado-Silva L, Azevedo L, Oliveira JAC, et al (2014). Sesame and resistant starch reduce the colon carcinogenesis and oxidative stress in 1,2- dimethylhydrazine-induced cancer in Wistar rats. Food Res Int, 62, 609-17.

Qi X, Cui C, Peng Y, et al (2013). Genetic evidence of paleolithic colonization and neolithic expansion of modern humans on the Tibetan plateau. Mol Biol Evol, 30, 1761-78.

Quassinti L, Maggi F, Barboni L, et al (2014). Wild celery (Smyrnium olusatrum L.) oil and isofuranodiene induce apoptosis in human colon carcinoma cells. Fitoterapia, 97,133-41.

Raghavan M, Skoglund P, Graf KE, et al (2014).Upper palaeolithic siberian genome reveals dual ancestry of Native Americans. Nature, 505, 87-91.

Ranzato E, Martinotti S, Calabrese CM, et al (2014). Role of nutraceuticals in cancer therapy. J Food Res, 3,18-24.

Reilly MT, Faulkner GJ, Dubnau J, et al (2013). The role of transposable elements in health and diseases of the central nervous system. J Neurosc, 33, 17577-86.

Reyes-Centeno H, Ghirotto S, Detroit F, et al (2014). Genomic and cranial phenotype data support multiple modern human dispersals from Africa and a southern route into Asia. Proc Natl Acad Sci USA, 111, 7248-53.

Ribeiro FA, Gomes de Moura CF, Aguiar O, et al (2014). The chemopreventive activity of apple against carcinogenesis: antioxidant activity and cell cycle control. Eur J Cancer Prev, 23, 477-80.

Richter D, Abarzua S, Chrobak M, et al (2013). Effects of phytoestrogen extracts isolated from pumpkin seeds on estradiol production and ER/PR expression in breast cancer and trophoblast tumor cells. Nutr Cancer, 65, 739-45.

Rizzo LY, Longato GB, Ruiz AL, et al (2014). In vitro, in vivo 
and in silico analysis of the anticancer and estrogen-like activity of guava leaf extracts. Curr Med Chem, 21, 2322-30.

Robles-Escajeda E, Lerma D, Nyakeriga AM, et al (2013). Searching in mother nature for anti-cancer activity: anti -proliferative and pro-apoptotic effect elicited by green barley on leukemia/lymphoma cells. PLoS One, 8, 73508.

Romano B, Fasolino I, Pagano E, et al (2014). The chemopreventive action of bromelain, from pineapple stem (Ananas comosus L.), on colon carcinogenesis is related to antiproliferative and proapoptotic effects. Mol Nutr Food Res, 58, 457-65.

Savio AL, Silva GN, Camargo EA, et al (2014). Cell cycle kinetics, apoptosis rates, DNA damage and TP53 gene expression in bladdercancer cells treated with allyl isothiocyanate (mustard essential oil). Mutat Res Fundam Mol Mech Mutagen, 762, 40-6.

Seki T, Maeda H (2010). Cancer preventive effect of Kumaizasa bamboo leaf extracts administered prior to carcinogenesis or cancer inoculation. Anticancer Res, 30, 111-8.

Shan S, Li Z, Newton IP, et al (2014). A novel protein extracted from foxtail millet bran displays anti- carcinogenic effects in human colon cancer cells. Toxicol Lett, 227, 129-38.

Shi H, Qi X, Zhong H, et al (2013). Genetic evidence of an East Asian origin and paleolithic northward migration of Y-chromosome haplogroup N. PLoS One, 8, 66102.

Shiezadeh F, Mousavi SH, Amiri MS, et al (2013). Cytotoxic and apoptotic potential of Rheum turkestanicum Janisch root extract on human cancer and normal cells. Iran J Pharm Res, 12, 811-9.

Stewart JR, Stringer CB (2013). Human evolution out of Africa: The role of refugia and climate change. Science, 335, 1317-21.

Suleria HA, Butt MS, Anjum FM, et al (2015). Onion: nature protection against physiological threats. Crit Rev Food Sci Nutr, 55, 50-66.

Sultana B, Anwar F, Mushtaq M, et al (2014). In vitro antimutagenic, antioxidant activities and total phenolics of clove (Syzygium aromaticum L.) seed extracts. Pak J Pharm Sci, 27, 893-9.

Summerer M, Horst J, Erhart G, et al (2014). Large-scale mitochondrial DNA analysis in Southeast Asia reveals evolutionary effects of cultural isolation in the multiethnic population of Myanmar. BMC Evol Biol, 14, 17.

Sutton KM, Greenshields AL, Hoskin DW (2014). Thymoquinone, a bioactive component of black caraway seeds, causes G1 phase cell cycle arrest and apoptosis in triple-negative breast cancer cells with mutant p53. Nutr Cancer, 66, 408-18.

Thuong PT,Hung TM, Khoi NM, et al (2014). Cytotoxic and anti-tumor activities of lignans from the seeds of Vietnamese nutmeg Myristica fragrans. Arch Pharm Res, 37, 399-403.

Vavilov NI (1951). The origin variation immunity and breeding of cultivated plants (translation by K Star Chester). Chron Bot, 13, 1-364.

Vizzotto M, Porter W, Byrne D, et al (2014). Polyphenols of selected peach and plum genotypes reduce cell viability and inhibit proliferation of breast cancer cells while not affecting normal cells. Food Chem, 164, 36-70.

Wang HW, Mitra B, Chaudhuri TK, et al (2011). Mitochondrial DNA evidence supports northeast Indian origin of the aboriginal Andamanese in the Late Paleolithic. J Genet Genomics, 38, 117-22.

Wang N, Wang W, Huo P, et al (2014). Mitochondria -mediated apoptosis in human lung cancer A549 cells by 4-methylsulfinyl -3-butenyl isothiocyanate from radish seeds. Asian Pac J Cancer Prev, 15, 2133-39.

Wikipedia (2013). Center of Origin.Available from: http:// en.wikipedia.org/wiki/Center_of_origin, access date
25/02/2013

Witas HW, Tomczyk J, Jędrychowska-Danska K, et al (2013). mtDNA from the early bronze age to the roman period suggests a genetic link between the indian subcontinent and mesopotamian cradle of civilization. PLoS One, 8, 73682.

Wu Q, Cho JG, Yoo KH, et al (2013). A new phenanthrene derivative and two diarylheptanoids from the roots of Brassica rapa ssp. campestris inhibit the growth of cancer cell lines and LDL-oxidation. Arch Pharm Res, 36, 423-9.

Wynn JG, Sponheimer M, Kimbel WH, et al (2013). Diet of australopithecus afarensis from the pliocene hadar formation, ethiopia. Proc Natl Acad Sci USA, 110, 10495-501.

Xi SY, Zhang Q, Liu CY, et al (2012). Effects of hydroxy safflower yellow-a on tumor capillary angiogenesis in transplanted human gastric adenocarcinoma BGC-823 tumors in nude mice. J Tradit Chin Med, 32, 243-8.

Xiang J, Xiang Y, Lin S, et al (2014). Anticancer effects of deproteinized asparagus polysaccharide on hepato- cellular carcinoma in vitro and in vivo. Tumour Biol, 35, 3517-24.

Xu X, Cheng Y, Li S, et al (2014). Dietary carrot consumption and the risk of prostate cancer. Eur J Nutr, 53, 1615-23.

Xu B, Chang SK(2012). Comparative study on anti- proliferation properties and cellular antioxidant activities of commonly consumed food legumes against nine human cancer cell lines. Food Chem, 134, 1287-96.

Yaffe PB, Power Coombs MR, Doucette CD, et al (2014). Piperine, an alkaloid from black pepper, inhibits growth of human colon cancer cells via G1 arrest and apoptosis triggered by endoplasmic reticulum stress. doi:10.1002/ mc.22176.

Yin X, Zhang R, Feng C, et al (2014). Diallyl disulfide induces $\mathrm{G} 2 / \mathrm{M}$ arrest and promotes apoptosis through the p53/p21 and MEK-ERK pathways in human esophageal squamous cell carcinoma. Oncol Rep, 32, 1748-56.

Zeng YW, Du J, Pu XY, et al (2011). Strategies of functional food for hypertension prevention in China. J Med Plants Res, 5, 5671-6.

Zeng YW, Pu XY, Du J, et al (2012). Use of functional foods for diabetes prevention in China. Afr J Pharm Pharmacol, 6, 2570-9.

Zeng YW, Yang JZ, Pu XY, et al (2013). Strategies of functional food for cancer prevention in human being. Asian Pac J Cancer Prev, 14, 1585-92.

Zhang D, Li YH, Mi M, et al (2013). Modified apple polysaccharides suppress the migration and invasion of colorectalcancer cells induced by lipopolysaccharide. Nutr $R e, 33,839-48$.

Zhang X, Qi X, Yang Z, et al (2013). Analysis of mitochondrial genome diversity identifies new and ancient maternal lineages in cambodian aborigines. Nat Commun, 4, 2599.

Zhang Q, Su B (2014). Evolutionary origin and human- specific expansion of a cancer/testis antigen gene family. Mol Biol Evol, 31, 2365-75.

Zhang W, Ming Q, Shi Z, et al (2014). Lake sediment records on climate change and human activities in the Xingyun Lake catchment, SW China. PLoS One, 9, 102167.

Zhao Y, Ren JL, Wang MY, et al (2013). Codon 104 variation of p53 gene provides adaptive apoptotic responses to extreme environments in mammals of the Tibet plateau. Proc Natl Acad Sci USA, 110, 20639-44.

Zhou MG, Wang XF, Hu JP, et al (2010). Geographical distribution of cancer mortality in China, 2004-2005. Chinese J Prevent Med, 44, 303-8.

Zhu RX, Potts R, Pan YX (2008). Early evidence of the genus homo in east Asia. J Hum Evol, 55, 1075-85. 